\title{
A new area classification for understanding internal migration in Britain
}

Adam Dennett* and John Stillwell*2

${ }^{* 1}$ Centre for Advanced Spatial Analysis, University College London

${ }^{* 2}$ School of Geography, University of Leeds

\section{Abstract}

This article details the development of a new area classification for Britain based on internal migration variables taken from the 2001 Census. An explanation of why general-purpose area classifications already in existence are not ideal for internal migration analysis is provided, before an account of the construction of the new classification is given. The latter involves justification of the choice of variables, explanation of the methodology adopted and presentation of the final typology. 


\section{Introduction}

In the 'Regions 2020' report (CEC 2008) commissioned by the European Union (EU) to assess the future challenges faced by EU regions as we head further into the third millennium, population change is one of the key issues identified alongside globalisation, climate change and energy consumption. All countries and regions within Europe will be affected by changes in their populations but many in quite different ways. The population of the United Kingdom (UK) is projected to keep rising over the next half century (Rees et al. 2010; ONS 2011) against a backdrop of low fertility and continued ageing, but these overall trends will mask much more nuanced sub-national changes in population magnitude and structure. Local variations in fertility and mortality will contribute to the evolving demographic profiles of areas, but migration will also contribute significantly to transforming the structure and composition of local populations across the country. In some cases, this migration will involve the movement of people internationally, but far more commonplace will be the movement of people to and from areas within the country through internal migration.

Understanding internal migration at a relatively small geographical scale is perhaps more important in the UK now than it has been at any previous time. The global financial crisis has led to the deepest recession experienced by the UK since the 1920s, posing real problems for those charged with governing the country. A new Coalition Government, sworn in in mid-2010, is determined to move power and funding away from central and regional government to more local authorities, scrapping Regional Development Agencies in the process (www.bbc.co.uk/news/10391326) and proposing to install Local Enterprise Partnerships (Larkin 2010), comprised of local authorities across city regions in many cases, to deal with resource allocation and planning which is driven, to a large extent, by the distribution of the population. The national statistical agencies are all concerned to improve the estimates of internal migration underpinning the mid-year estimates that form the basis for resource allocation.

So there is a continuing and perhaps increasing need to understand, at a local level, the patterns of internal migration that contribute to sub-national population change, but this presents a challenge since patterns of internal migration in Great Britain (GB) are complex and varied and thus can evade easy comprehension - the 408 local authorities in England, Wales and Scotland present some 166,464 possible internal migration interactions. In an effort to reduce the complexity of internal migration, work by Dennett and Stillwell (2010b) and Raymer and Giulietti (2009) has made use of general-purpose area classifications which group areas with similar overall population characteristics into clusters, reducing the number of origins and destinations. However, as indicated by Duke-Williams (2010), migrant populations do not necessarily share the same characteristics as settled populations and thus the use of general-purpose classifications in migration analysis may confound important patterns where similar types of migration flow are obscured by clusters in the classification defined by different underlying populations. If this is indeed the case, then a more useful system for reducing the complexity of internal migration flows and aiding comprehension would be a bespoke migration-based classification for migration analysis. Such a classification would offer a secondary benefit through producing an area typology which would distil the key features of the internal migration landscape of Britain into a more accessible system defined by its dominant characteristics. 
Thus, in this article we report on the development of a new classification of local authority districts in $G B$, designed with the specific purpose of enhancing the understanding of internal migration in Britain. To this end, the article has some broad aims embodied in two principal research questions: the first asks why the readily available general-purpose classifications already in existence are not wholly sufficient for assisting internal migration analysis; the aim being that through answering this question, a justification for developing a new bespoke migration-based classification, distinct from other general-purpose classifications which use the whole population, can be achieved. The second question asks what a new migration-based area classification typology would consist of, look like and reveal about the internal migration landscape of Britain; the aim is that through providing an overview of the data used, methodology employed and typology produced, a new perspective on the internal migration narrative in Britain will be achieved and a new tool for analysis will be available.

We should note that in order to answer fully this second research question and say definitively what this new classification reveals about the internal migration landscape of Britain, a comparative analysis of the same internal migration flow data using a general-purpose classification and our new migration-based classification should be carried out. Unfortunately such an analysis is beyond the scope of this article - here our focus is on theoretical justification, methodological considerations and demonstrable outcomes pertaining specifically to the new classification itself. However, we believe that we are able to answer much of this second question within the remit we have set ourselves, with the cluster profiles described in the results section revealing much about the associations between areas and types of migrant in Britain in a way that has not been explored before.

A final subsidiary aim to this article is to make some points in relation to classification building methodology. We are aware that area classifications are useful analysis tools; however, their utility can be markedly increased through correct specification and methodological rigour. We therefore aim to present some methodological advice borne out of our own experimentation for anyone embarking on a similar piece of research in the future.

\section{The case for a new classification}

So is there a theoretical justification that can be made for a new migration-based classification? With dual origin and destination geographies, internal migration data are considerably more complex than standard single-zone geographical data. As noted in the introduction section, even in a spatial system containing just a few hundred zones, for every zone in the system the potential for an interaction to occur with every other zone means that the whole system consists of a large number of origin to destination flows (the number of zones squared). Consequently, a number of pieces of migration research (Dennett and Stillwell 2010b; Raymer and Giulietti 2009; Rees et al. 1996) have made use of existing classification systems which group together zones with similar population characteristics, greatly reducing the number of origins and destinations and facilitating analysis.

Area classifications take large sets of often very spatially and characteristically heterogeneous zones and group them into a much smaller number of clusters of zones which are more characteristically homogenous. A number of different area classifications exist in the UK at a variety of spatial scales. In the commercial sector, companies such as $\mathrm{CACl}$ (with the ACORN 
classification), Experian (Mosaic), Call Credit (CAMEO) and Acxiom (PersonicX) have all developed area classifications for small-scale, postcode (and even down to the household and individual) geographies to serve their own market interests. Outside the commercial sector, the Office for National Statistics (ONS) in the UK has, for many years, produced a series of classifications for academic and governmental use, based on the outputs of the national censuses. In 2001, national classifications were produced for a range of geographies from very small output areas (Vickers and Rees 2006, 2007) to Health Authority areas and Local Authority districts (Bailey et al. 2000). Other organisations have produced their own specific-purpose classifications, for example the Department for Food and Rural Affairs (DEFRA) has built an Urban/Rural classification (www.defra.gov.uk/evidence/statistics/rural/rural-definition.htm). There are also other independently produced general-purpose schemas in the public domain such as the local authority classification developed by Vickers et al. (2003).

So why are these classifications not entirely suitable for internal migration analysis? First, not all of these classifications are available or appropriate for use. The analysis of internal migration flows in the context of classification systems is to a certain extent constrained by the limitations of the data available. Currently the most reliable and spatially detailed source of internal migration data originates from the 2001 Census, but whilst these data are spatially very detailed - available down to the level of Output Area - the huge number of origin/destination links at this level (almost 50 billion!) means that the 10 per cent of the population who were recorded as internal migrants are spread very sparsely across the matrix of interactions. This would not be a huge issue were the raw data published, as despite the potential pitfalls associated with the reliability of small counts, these counts could still be used in an analysis. Unfortunately, however, any small flow (of one or two people) in England and Wales is adjusted (randomly to either a 0 or 3 ) to preserve the confidentiality of respondents (Duke-Williams and Stillwell 2007; Stillwell and Duke-Williams 2007), thus precluding the (useful) appropriation of much of these data. Sparse data matrices and small cell adjustment mean that the quality of the data at the small scale is poor outside of anywhere but the most populous areas, and so the use of small area classifications in the analysis of internal migration has not been popular, with the notable exception of work by Duke-Williams (2010).

So why not analyse internal migration data from another source if problems exist with Census data? Unfortunately, availability of non-census internal migration data is limited. As is detailed by Dennett et al. (2007), only a few non-census national datasets in the UK provide information on internal migration. The best comes from National Health Service (NHS) sources in the form of the NHS Central Register and locally held general practitioner patient registers, but the most detailed spatial resolution of these data is the local authority district (at least in the published data - as Chappell et al. (2000) note, postcodes of present and previous residence are contained in patient registers pre-publication). Consequently any non-census based analysis of internal migration which intends to make use of an area classification is forced to use a local authority district classification.

So returning to the original question, why are the general purpose local authority classifications such as those produced by ONS and Vickers et al. (2007) not entirely suitable for internal migration analysis? As has already been noted, a number of pieces of work have made use of district level area classifications in their analysis. Champion et al. (2007) opt for a straightforward metropolitan/non-metropolitan distinction in part of an analysis of migration and socio-economic change; Raymer and Giulietti (2009) make use of the ONS classification of local authority districts; 
however, Dennett and Stillwell (2010b) choose to use another classification of districts developed by Vickers et al. (2003).

If these different typologies have been used, perhaps one might be more suitable than another? Both the ONS and the Vickers et al. classifications are similar general-purpose classifications in that they both take their data from across the variable domains of the 2001 Census, looking to incorporate a wide range of characteristics in order to maximise their utility to the widest range of users. Both are three tier hierarchies whereby the clusters at the top of the hierarchy can be subdivided into lower tiers which maintain similarities with the tier above. Both make use of Ward's hierarchical clustering algorithm in constructing the typology. Whether two classifications borne of similar data, using similar techniques and with similar outcomes can be judged with one superior to another for the analysis of migration data, is a difficult question to answer. Some may argue that the Vickers et al. classification makes a more logical distinction between urban and rural districts with many areas which would be classified as 'rural' in the DEFRA classification coming under the 'prospering smaller towns' label in the ONS classification, and perhaps the Vickers et al. classification provides a more comprehensive methodology to accompany the classification, but the ONS classification, on the other hand, holds 'National Statistic' status and thus has been certified to be in accordance with the 'code of practice for official statistics'. It is difficult to conclude that one of these two general-purpose classifications is better than the other and therefore suggest why either might be less than ideal for internal migration analysis.

The answer, as hinted at by Duke-Williams (2010), is that the general population is not representative of the internal migrant population, and so examining flows between types of area defined differently can cloud some of the important patterns present in the system. Both the classifications developed by Vickers et al. and the ONS define clusters using a suite of variables which, whilst covering the main domains of the Census, such as age, ethnicity, family status, housing tenure, qualifications, employment status, car ownership, industry of employment, health and socio-economic status, do not include any variables relating to internal migration status. It could be argued that by not including migrants in the classification, any patterns observed when examining migration data through the classification lens can be seen to be independent of the influence of migration variables in the classification (high volumes of in-migrants are not just going to clusters characterised by in-migration for example), and thus relationships between migration and other variables could be observed. However this situation can be viewed from a different perspective; if the settled population of an area is actually quite different from the migrant population, then it could be that some migration patterns might be obscured by the cluster groups defined from the general population - an obvious example would be the flows of students into cities with quite different populations but similarly large student populations such as Cambridge, Birmingham or Leeds; were these cities in the same cluster, the flows into these cities would be shown as far more concentrated and significant than if they were in three separate clusters (as they are in the Vickers et al. (2003) classification). The argument would continue that if this is the case with other districts, then it is likely that a specific-purpose internal migration classification might offer a more useful typology for analysing migration data as patterns of migration would not be obscured by variations in the underlying population between areas influencing the typology.

In order to assess whether this is a valid argument, we need to know how far the overall population differs from the internal migration population (across different areas), and whether any variation is consistent. To do this here we compare, for each district in Britain, the variation across different 
variables for the total and migrant populations using the 2001 Census. So, for example, if 50 per cent of the total population of an area is aged 16-29, is the percentage also reflected in the migrant populations, and if it is not, is the degree of variation consistent across all districts in Britain? If the percentages are similar, then we can say for this variable the migrant population is representative of the underlying population; however, if they are not then we can conclude that the two populations bear little relationship for that given variable. It is likely that different areas will be more similar than others and the degree of difference will vary between districts; therefore, if we assess the correlation between the migrant population and the general population across a number of districts we can begin to understand the degree to which the populations differ across the whole system. We should point out that the total population recorded in an area the end of a census period will also partially contain some in-migrants; therefore, in this exploratory exercise this will have to be borne in mind.

\section{A comparison of population and migration distributions}

To ascertain the degree of correlation between migrant and total populations, we selected suites of variables from across six census domains - age, ethnicity, socio-economic status, economic activity, housing tenure and family status. Within each domain a number of variables comprise the total population, so for each variable we calculated the proportion of the total migrant and overall populations represented before assessing the correlation between the two proportions. Figure 1 exemplifies the correlation between two of the variables - in this case the proportion of the total population which is economically inactive, against the proportion of the out-migrant population which is economically inactive for each GB district. In this case we can see a very weak positive correlation with an $\mathrm{R}^{2}$ value of around 19 per cent.

Figure $1 \quad$ Correlation across 408 GB districts between the proportion of economically inactive out-migrants and the proportion of the economically inactive overall population

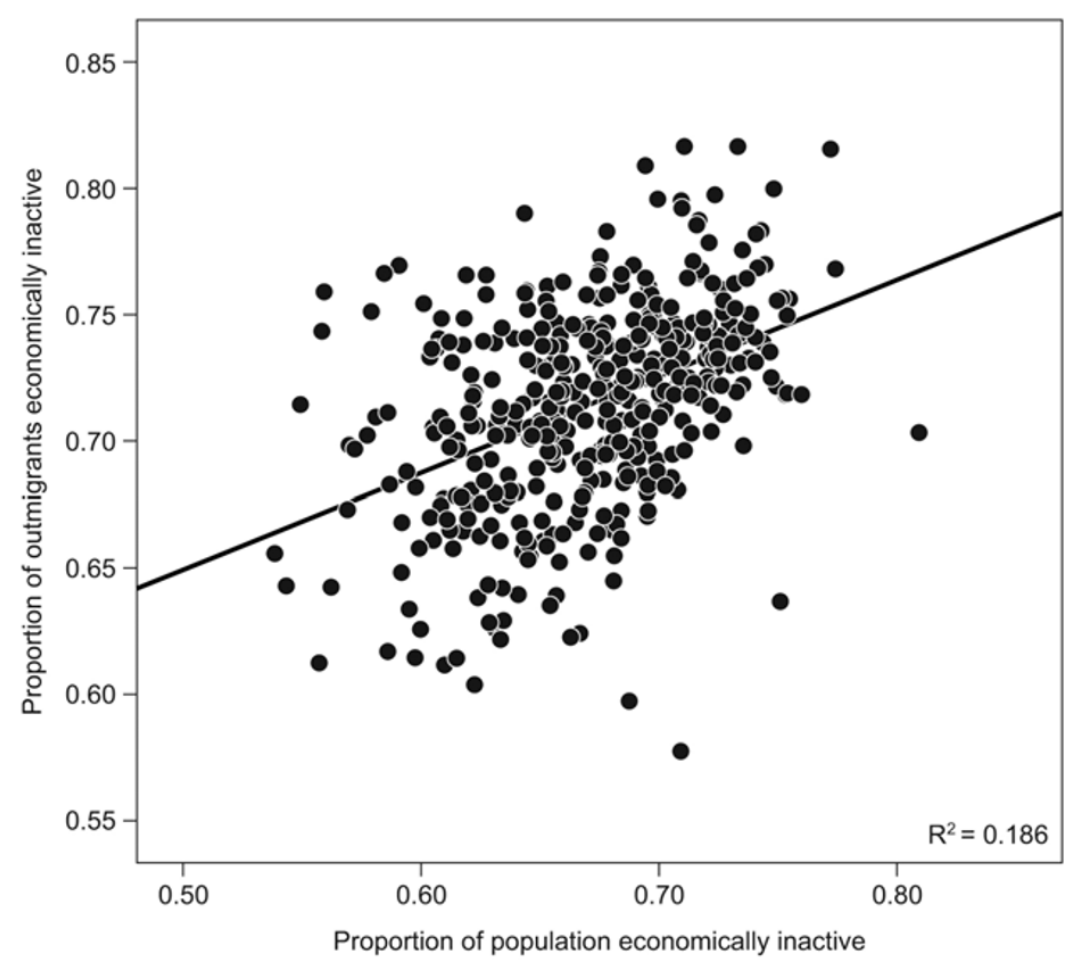


Similar correlations were carried out for in-migration, out-migration and within-area migrant variables with the overall populations across the variable domains (Table 1). The first point of note is that in most cases the correlation coefficients are higher for in-migration than out-migration, with the coefficients for within-area migration the highest of all. This would make sense given the point made earlier that in-migrants will also be represented in the overall population of each district at the end of the measurement period, as will within-area migrants. There is of course some variation: for example, the correlation between in-migrants and the total population is very much higher than for out-migrants at age 16-29 (around 80 per cent) - a correlation perhaps not unexpected given the much higher proportion of the total population that will be migrants at this age and the typical urban destinations of these migrants - whereas at age 30-44, the correlation is far higher for outmigration, perhaps reflecting a dispersal of migrants at this age group.

\section{Table 1 Correlation between general population attributes and migrant attributes for $408 \mathrm{~GB}$ districts}

\begin{tabular}{|l|lll|}
\cline { 2 - 4 } \multicolumn{1}{c|}{} & \multicolumn{3}{|c|}{$\mathrm{R}^{2}$} \\
\hline Attribute & In-migration & $\begin{array}{l}\text { Out- } \\
\text { migration }\end{array}$ & $\begin{array}{l}\text { Within-area } \\
\text { migration }\end{array}$ \\
\hline Age 0-15 & 0.13 & 0.28 & 0.44 \\
Age 16-29 & 0.80 & 0.29 & 0.71 \\
Age 30-44 & 0.14 & 0.68 & 0.37 \\
Age 45-59 & 0.47 & 0.52 & 0.59 \\
Age 60 plus & 0.73 & 0.64 & 0.78 \\
\hline Non-white & 0.82 & 0.94 & 0.98 \\
\hline NS-SEC 1.1 & 0.79 & 0.75 & 0.91 \\
NS-SEC 1.2 & 0.82 & 0.59 & 0.94 \\
NS-SEC 2 & 0.68 & 0.57 & 0.88 \\
NS-SEC 3 & 0.61 & 0.29 & 0.77 \\
NS-SEC 4 & 0.59 & 0.27 & 0.85 \\
NS-SEC 5 & 0.61 & 0.42 & 0.70 \\
NS-SEC 6 & 0.62 & 0.56 & 0.77 \\
NS-SEC 7 & 0.71 & 0.55 & 0.85 \\
NS-SEC 8 & 0.35 & 0.37 & 0.72 \\
NS-SEC Student & 0.65 & 0.09 & 0.84 \\
NS-SEC not classified & 0.56 & 0.58 & 0.72 \\
\hline Economically Inactive & 0.54 & 0.19 & 0.69 \\
\hline Owner Occupied & 0.54 & 0.14 & 0.73 \\
Socially Rented & 0.55 & 0.26 & 0.75 \\
Privately Rented & 0.61 & 0.28 & 0.68 \\
\hline Living Alone & 0.52 & 0.06 & 0.57 \\
Living in a couple Family & 0.76 & 0.31 & 0.70 \\
Single Parent family & 0.46 & 0.34 & 0.67 \\
Non-Family Household & 0.80 & 0.37 & 0.53 \\
\hline
\end{tabular}


Overall, the correlations between the migrant populations and overall populations across all British districts can be seen as moderate to weak, especially for out-migration. Even where correlations are relatively strong across all domains for within-area migration, an $\mathrm{R}^{2}$ value of 70 per cent will still mean that 30 per cent of the variation in migration is not accounted for by variation in the population. From this exploratory analysis we are able to conclude that, on the whole, there is a noticeable difference between the overall population and the internal migrant populations across all variable domains and across most districts in the country. This would indicate that little information about internal migrants in Britain can be inferred from the general-purpose classifications described earlier and thus a new bespoke classification based upon internal migration variables would certainly offer a new and potentially more useful lens through which to examine internal migration. As well as being less likely to mask important patterns, a classification constructed from attribute rich 2001 Census data offers the secondary benefit of enhancing any more attribute-poor non-census data examined using the typology.

One further justification exists for creating a new internal migration area typology. Such a classification would also be useful in its own right and not just as a vehicle for reducing the number of origins and destinations to consider in an analysis. The process of evaluating and selecting variables means that only those which are important to the overall internal migration landscape of Britain will be included. Once complete, an area typology will make it possible to identify those areas in the country exhibiting similar internal migration profiles and thus offer an additional perspective not before seen in Britain.

\section{The CIDER Migration Classification}

Having addressed our first research question which relates to theoretical justification, we now turn our attention to the second research question which asks what a new migration-based area classification typology would consist of, look like and reveal about the internal migration landscape of Britain. In answering this question we will briefly outline the data used and the methodology employed to construct the classification, before presenting the new typology.

\section{Data}

As discussed in the previous section, an internal migration-based classification designed to facilitate further analysis will need to be built at the local authority district level - consequently the classification will only be for Great Britain rather than the whole UK (including Northern Ireland) as equivalent census internal migration data are not available for Northern Ireland Districts. The richest source of data available is the census, with the 2001 Census Special Migration Statistics (SMS) providing flow matrices from which in-migration, out-migration and within district migration flows can be calculated. We should note that some may define within-district flows as 'residential mobility' rather than migration - here we choose not to make this distinction and adopt the UK Census definition of migration as districts are sufficiently large spatial units to accommodate the kind of status changing moves more associated with migration. These data are freely available to academic users via the Centre for Interaction Data Estimation and Research (CIDER http://cider.census.ac.uk) through the WICID interface. At level 1 - the local authority district level 11 tables of internal migration data are available, containing almost 1,000 variables; these are shown in Table 2. 


\section{Methodology}

Classification building stems from cluster analysis and as such has a well-established history. Consequently, we do not look to offer here a radically different approach, rather an incremental development and novel application of a popular methodology last put to good use by Vickers and Rees (2007) in the creation of the ONS Output Area classification (OAC), but earlier advocated by Everitt et al. (2001) after first being proposed by Milligan and Cooper (1987). We should note that there is a particular branch of classification - functional regionalisation, where flows themselves are used to define homogenous and distinct catchments (see work by Coombes et al. 1986; Coombes 2002; Coombes et al. 2004, for application in the UK) - which we have not employed here. Functional regionalisation tends to cluster contiguous areas into discrete zones or catchment localities which stand alone as distinct regions. Here our interest is in spatially diffuse zones which might share similar characteristics and therefore we choose to pursue a conventional cluster analysis methodology.

\section{Table $2 \quad$ Tables available from the 2001 SMS at level 1 and literature linking variables to explanations of migration patterns and propensities}

\begin{tabular}{|c|c|c|c|}
\hline \begin{tabular}{|l|} 
Table \\
Reference
\end{tabular} & \begin{tabular}{|l|} 
Table Name $I$ \\
variables included
\end{tabular} & \begin{tabular}{|c|} 
Cells $/$ \\
variables \\
within \\
table
\end{tabular} & Literature linking variable to migration patterns and propensities \\
\hline Table 1 & $\begin{array}{l}\text { Family status of } \\
\text { migrant }\end{array}$ & 75 & $\begin{array}{l}\text { Age: Bates and Bracken 1982; Dennett and Stillwell 2010b; } \\
\text { Raymer et al. 2006; Raymer and Rogers 2007; Rogers and } \\
\text { Castro 1981; Rogers et al. 2002; Uren and Goldring } 2008 \\
\text { Sex: Champion 2005, Dennett and Stillwell 2010a } \\
\text { Cooke 2008; Geist and McManus 2008; Boyle et al. 1999; } \\
\text { Cooke and Bailey 1999; Castro and Rogers } 1981\end{array}$ \\
\hline Table 3 & $\begin{array}{l}\text { Ethnic group by sex } \\
\text { (GB destinations) }\end{array}$ & 24 & $\begin{array}{l}\text { Faggian et al. 2006; Finney and Simpson 2008, 2009; Owen } \\
\text { 1997; Raymer et al. 2009; Raymer and Giulietti 2009; Simpson } \\
\text { and Finney 2009; Stillwell et al. 2008; Stillwell; 2010a; 2010b }\end{array}$ \\
\hline Table 3n & $\begin{array}{l}\text { Ethnic group by sex } \\
\text { (Northern Ireland } \\
\text { destinations) }\end{array}$ & 9 & See Table 3 \\
\hline Table 4 & $\begin{array}{l}\text { Whether suffering } \\
\text { limiting long term } \\
\text { illness by whether } \\
\text { in household by sex } \\
\text { by age }\end{array}$ & 84 & Norman et al. 2005 \\
\hline Table 5 & $\begin{array}{l}\text { Economic activity } \\
\text { by sex }\end{array}$ & 42 & $\begin{array}{l}\text { Ravenstein 1885; 1889, Fielding } 1992 \text { and Findlay et al. 2009; } \\
\text { Bohara and Krieg 1998; Dixon 2003; Böheim and Taylor } 2002\end{array}$ \\
\hline Table 6 & Moving groups & 16 & \\
\hline Table 7 & $\begin{array}{l}\text { Moving groups by } \\
\text { tenure }\end{array}$ & 32 & $\begin{array}{l}\text { Boyle 1998; Cameron et al. 2005; Murphy et al. 2006; Clark } \\
\text { and Huang } 2004\end{array}$ \\
\hline Table 8 & $\begin{array}{l}\text { Moving groups by } \\
\text { economic activity } \\
\text { by sex }\end{array}$ & 336 & See Table 5 \\
\hline Table 9 & $\begin{array}{l}\text { Moving groups by } \\
\text { NS-SEC of group } \\
\text { reference person }\end{array}$ & 288 & $\begin{array}{l}\text { Champion et al. 2007; Champion and Combes 2010; Sjaastad } \\
1962\end{array}$ \\
\hline Table 10 & $\begin{array}{l}\text { Migrants in } \\
\text { Scotland/Wales/Nor } \\
\text { thern Ireland with } \\
\text { some knowledge of } \\
\text { Gaelic/Welsh/Irish }\end{array}$ & 36 & \\
\hline
\end{tabular}


After deciding on the objects to be clustered - in this case the 408 local authority districts of Great Britain - the first major decision relates to the variables used to define the clusters. Throughout the literature, warnings abound that choosing appropriate variables is very important, if not key, to the success of the final classification produced. While the use of statistical techniques can certainly help whittle down the choice of variables systematically, Openshaw and Wymer (1995, p.244) suggest that '[t]here is no statistical technique that is a good substitute for thinking about choice of variable, yet!' Certainly in the case of a migration-based classification, careful thought should be given to whether particular variables are likely to influence migration events or patterns. As is shown in Table 2, however, research has been carried out linking most of the variables available in level 1 of the SMS to migration patterns and propensities thus justifying at least initial inclusion in any classification based on migration variables.

Consequently for the 'Migration Classification', we select variables from all SMS tables except tables $3 n, 6$ and 10. The tables contain a total of 599 variables; however unlike a standard area classification where the variable relates to a static individual residing in that place, for every district in a migration-based classification, each variable needs to be further defined by its movement component. For example, for any one area in a standard classification, there could be a count of individuals of a particular age and sex. These individuals could be divided by a total population in that area and be represented as a proportion. When we add an interaction component, the area could be either a destination for in-migrants, or an origin for out-migrants, or indeed both for withinarea migrants. Straight away, just by identifying migrants as in-migrants, out-migrants or within district migrants, we have created three times as many variables from our original count. Where these counts can be divided by populations to create inflow, outflow and within-area migration rates, this number is doubled again.

In addition to standard rates and counts associated with internal migration, there are supplementary counts and rates that can be attached to most variables for all areas. For example, in-migration from the 'no usual address' category in the census (which comprise a considerable number of migrants) can also be included. Bell et al. (2002) detail a range of different measures which can be computed from flow data such as migration efficiency area connectivity or distance migrated. If the 14 indices outlined by Bell et al. (2002) alone were calculated for each variable in Table 1 then it is possible to see that very quickly the number of variables which could potentially be included in a classification becomes huge, numbering in the many thousands.

Faced with a vast number of potential variables which can be included in the classification, systematic process of variable reduction is used to reduce the large set of initial variables to a manageable list. We will not explain the process in great detail here, but will outline some of the considerations and techniques employed to affect the reduction. In classification construction, including two highly correlated variables is inadvisable as this effectively gives a double weight to the underlying phenomenon; therefore analysis of correlation statistics allows for such pairs to be identified and one variable to be dropped from the list (the choice often determined by how many other variables the candidate variable is also correlated with). For example, in the Migration Classification, correlation analysis quickly identified male and female variables as highly correlated and so by dropping both in favour of a combined sex variable immediately reduced the number of variables by two thirds. Principal components analysis can also be used, not to create new factors to include in the classification, but heuristically with variables displaying higher eigenvalues deemed more important within the dataset and thus better candidates for inclusion. In addition an 
assessment of variable skewness can also be carried out, discarding the most highly skewed variables as these will bias cluster formation. After this variable reduction process, the final list of variables still cover most of the domains in Table 2, excluding only limiting long term illness (dropped as highly skewed and adds little discriminatory power to classification after tests) and sex (males highly correlated with females). The final list of 44 variables chosen to define the Migration Classification is shown in Table 3.

Rates using a population denominator taken from the 2001 Census Key Statistics and Standard Tables, rather than raw counts, were selected in order that clusters were not biased by the differing flow volumes associated with areas with different sized populations. Note that variables 19 to 39 are migration efficiencies (using the total volume of in-migration and out-migration for each district as a denominator) as these are household variables which do not have suitable population denominators. All variables were standardised across the same range using z-scores as the standard rate and efficiency measurements are measured on different scales. Whilst other methods of standardisation could have been adopted, such as those described by Milligan and Cooper (1988), work by Schaffer and Green (1996) indicates that the precise method of standardisation matters less to the overall outcome of the classification than the choice of clustering algorithm or the choice of variables. Thus, z-scores, as a common standardisation method, were selected in this case.

A plethora of different clustering techniques can be applied to find groups within data. In the Vickers et al. (2003) and ONS (Bailey et al. 2000) local authority district classifications, Ward's clustering algorithm (Everitt et al. 2001) was applied to create the typologies. As described by Vickers and Rees (2007), Ward's method can be vulnerable to producing sub-optimal cluster solutions as in this hierarchical process, once a cluster has been created, it cannot be dissolved to find a better solution. Consequently the k-means algorithm (described by Everitt et al., 2000, as an optimisation algorithm as it will iteratively re-allocate objects to clusters until the best solution is found) was used to cluster the data in the Migration Classification.

Vickers and Rees $(2006,2007)$ used the SPSS programme to implement k-means, but our experiments have shown that running k-means in SPSS can prove problematic as SPSS assigns rigid initial cluster centroids, meaning that while an optimum local solution for those centroids is found, an optimum global solution may not be found. Figure 2 exemplifies this showing the two very different cluster solutions produced using a k-means algorithm in SPSS on the same dataset when the districts were sorted alternatively by name and code and then clustered into eight groups.

We discovered that one solution to this issue was to implement the k-means algorithm in the MATLAB programme. MATLAB has several advantages over SPSS, the first being that the optional 'replicates' parameter will run the algorithm for a set number of iterations using a different set of initial cluster seeds each time, only outputting the best global solution. Another advantage is that MATLAB also allows for different distance measures to be used to assess the distance each object in the classification is from its cluster centroid. In the creation of the Output Area classification, Vickers and Rees (2007) chose Euclidean distance: however, work by Aggarwal et al. (2001) has shown that for high dimensional datasets (high dimensions begin over 20 in their example - here we have 44), a measure of Manhattan distance improves the final cluster solution. 


\section{Table $3 \quad$ Final list of variables used in the Migration Classification}

\begin{tabular}{|c|c|}
\hline & Variable \\
\hline $\begin{array}{l}1 \\
2\end{array}$ & $\begin{array}{l}\text { In-migration rate of persons aged } 16 \text { to } 29 \\
\text { In-migration rate of persons aged } 30 \text { to } 44\end{array}$ \\
\hline 3 & In-migration rate of persons aged 45 to 59 \\
\hline 4 & In-migration rate of persons aged over 60 \\
\hline 5 & Out-migration rate of persons aged 16 to 29 \\
\hline 6 & Out-migration rate of persons aged 30 to 44 \\
\hline 7 & Out-migration rate of persons aged 45 to 59 \\
\hline 8 & Out-migration rate of persons aged over 60 \\
\hline 9 & Within-area migration rate of persons aged 16 to 29 \\
\hline 10 & Within-area migration rate of persons aged 30 to 44 \\
\hline 11 & Within-area migration rate of persons aged 45 to 59 \\
\hline 12 & Within-area migration rate of persons aged over 60 \\
\hline 13 & In-migration rate from no previous address of persons aged over 60 \\
\hline 14 & Internal in-migration rate of non-whites \\
\hline 15 & Internal within-area migration rate of non-whites \\
\hline 16 & In-migration rate from no previous address of non-whites \\
\hline 17 & In-migration rate of economically inactive individuals \\
\hline 18 & Out-migration rate of economically inactive individuals \\
\hline 19 & Migration efficiency of wholly moving households whose household reference person is in NS-SEC category 1.1 \\
\hline 20 & Migration efficiency of other moving groups whose household reference person is in NS-SEC category 1.1 \\
\hline 21 & Migration efficiency of wholly moving households whose household reference person is in NS-SEC category 1.2 \\
\hline 22 & Migration efficiency of other moving groups whose household reference person is in NS-SEC category 1.2 \\
\hline 23 & Migration efficiency of wholly moving households whose household reference person is in NS-SEC category 2 \\
\hline 24 & Migration efficiency of other moving groups whose household reference person is in NS-SEC category 2 \\
\hline 25 & Migration efficiency of wholly moving households whose household reference person is in NS-SEC category 3 \\
\hline 26 & Migration efficiency of other moving groups whose household reference person is in NS-SEC category 3 \\
\hline 27 & Migration efficiency of wholly moving households whose household reference person is in NS-SEC category 4 \\
\hline 28 & Migration efficiency of wholly moving households whose household reference person is in NS-SEC category 5 \\
\hline 29 & Migration efficiency of wholly moving households whose household reference person is in NS-SEC category 6 \\
\hline 30 & Migration efficiency of other moving groups whose household reference person is in NS-SEC category 6 \\
\hline 31 & Migration efficiency of wholly moving households whose household reference person is in NS-SEC category 7 \\
\hline 32 & $\begin{array}{l}\text { Migration efficiency of wholly moving households whose household reference person is in NS-SEC category Full } \\
\text { Time Student }\end{array}$ \\
\hline 33 & $\begin{array}{l}\text { Migration efficiency of other moving groups whose household reference person is in NS-SEC category Full Time } \\
\text { Student }\end{array}$ \\
\hline 34 & $\begin{array}{l}\text { Migration efficiency of wholly moving households whose household reference person is in NS-SEC category Not } \\
\text { Classified }\end{array}$ \\
\hline 35 & $\begin{array}{l}\text { Migration efficiency of other moving groups whose household reference person is in NS-SEC category Not } \\
\text { Classified }\end{array}$ \\
\hline 36 & Migration efficiency of wholly moving households moving into or from owner occupied accommodation \\
\hline 37 & Migration efficiency of other moving groups moving into or from owner occupied accommodation \\
\hline 38 & Migration efficiency of wholly moving households moving into or from privately rented accommodation \\
\hline 39 & Migration efficiency of other moving groups moving into or from privately rented accommodation \\
\hline 40 & Migration efficiency of individuals living alone \\
\hline 41 & Migration efficiency of individuals not living in a family but with others in a household \\
\hline 42 & Migration efficiency of individuals who are part of a couple family \\
\hline 43 & Migration efficiency of individuals who are part of a lone parent family \\
\hline 44 & Migration efficiency of individuals living in a communal establishment \\
\hline
\end{tabular}




\section{Figure $2 \quad$ Alternative outcomes from SPSS of the k-means clustering of 408 districts into 8 groups using 56 variables}

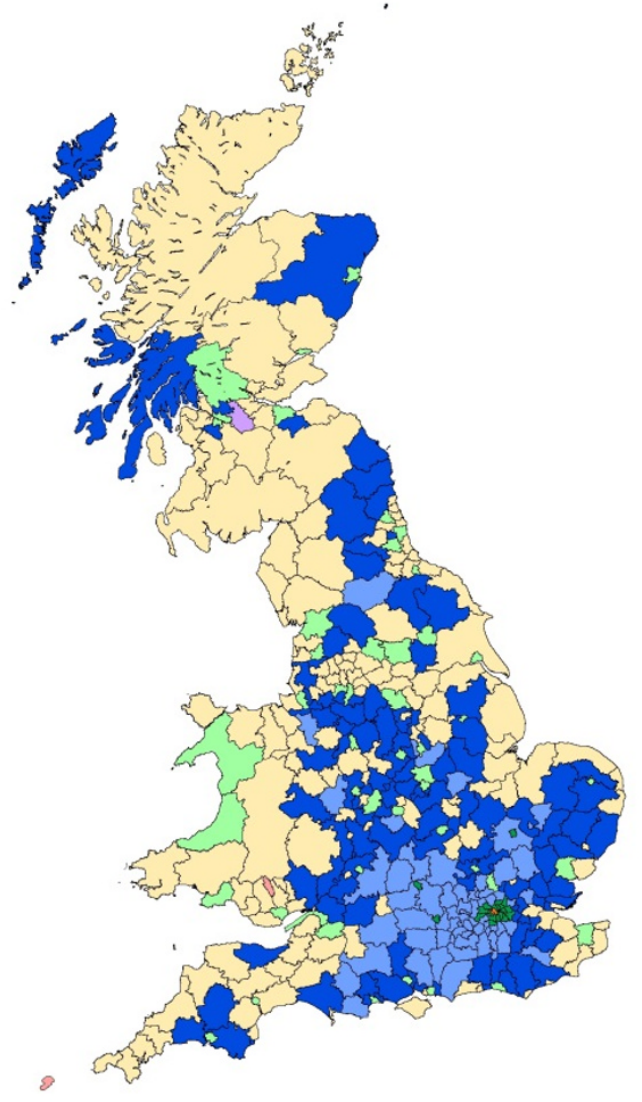

a) Cases sorted by district name

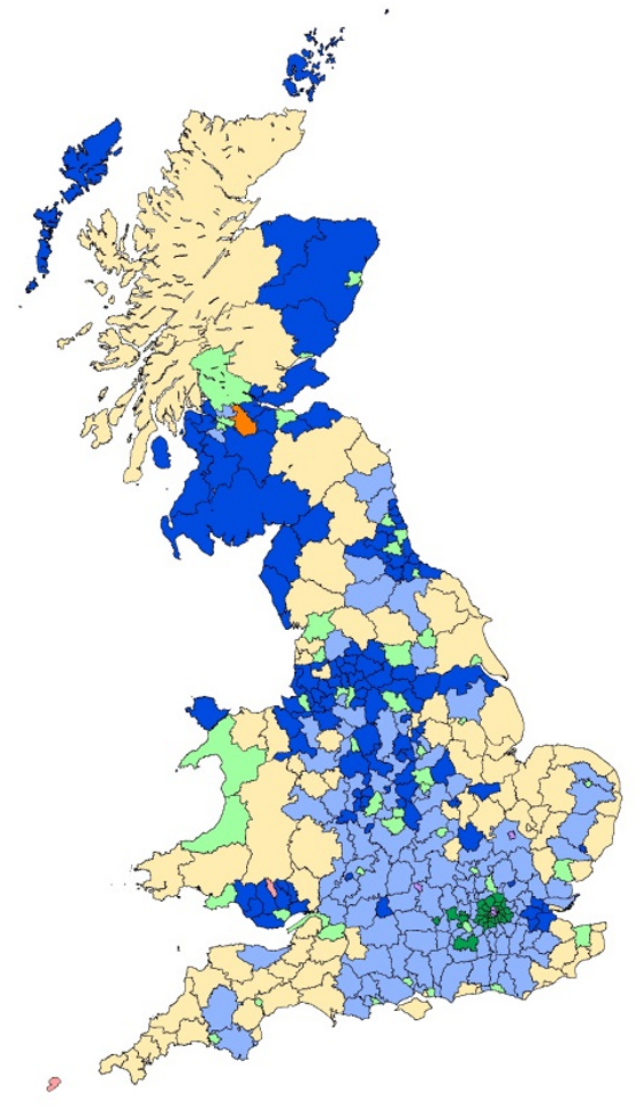

b) Cases sorted by district code

The final decision to be made concerns the number of clusters to be included in the classification. One of the difficulties with using k-means over a hierarchical algorithm is that the number of clusters $\mathrm{k}$ needs to be defined at the outset. As with many elements of classification building, the literature offers no definitive answer for deciding the most appropriate value of $k$. One particular method invented by Rousseeuw (1987), recommended by Kaufman and Rousseeuw (2005), espoused by MathWorks (2009) and implemented as the principal method to decide the number of clusters in the classification developed by Shepherd (2006), is the interrogation of 'silhouette' plots and values. A silhouette plot is a graphical representation of the average dissimilarity between any 'object' (in our case a district) within a cluster and other objects within both its own cluster and those in other clusters. The plots are represented on an index of -1 to +1 . A value close to +1 signifies that that object is nearer to its own cluster than any other. A value close to -1 suggests that the object might well be better placed in another cluster. Zero signifies that it is unclear whether that object is better placed in its current cluster or another.

A silhouette s value for any object $(i)$ in a cluster can be defined thus:

$s(i)=\frac{b(i)-a(i)}{\max \{a(i), b(i)\}}$

where 
$a(i)=$ the average dissimilarity of $i$ to all other objects in the same cluster; and

$b(i)=$ lowest average dissimilarity of $i$ to the objects in all other clusters in the whole solution

Where the most appropriate number of clusters was not known, k-means was run for a range of clusters from 2 to 14 each using 200 replicates to attain a more probable global minimum. This range of clusters was chosen as it was felt likely that the optimum solution would fall somewhere within this range - earlier experimentation with Ward's algorithm on this dataset had suggested eight clusters were most appropriate, Vickers (2006) suggests that around six may be a useful place to start, whereas Shepherd (2006) tests a range between 5 and 25. Silhouette and cluster size diagnostics were produced for each of the cluster solutions and are shown in Figures $\mathbf{3}$ and 4.

\section{Figure $3 \quad$ Average silhouette width values for solutions between 2 and 14 clusters}

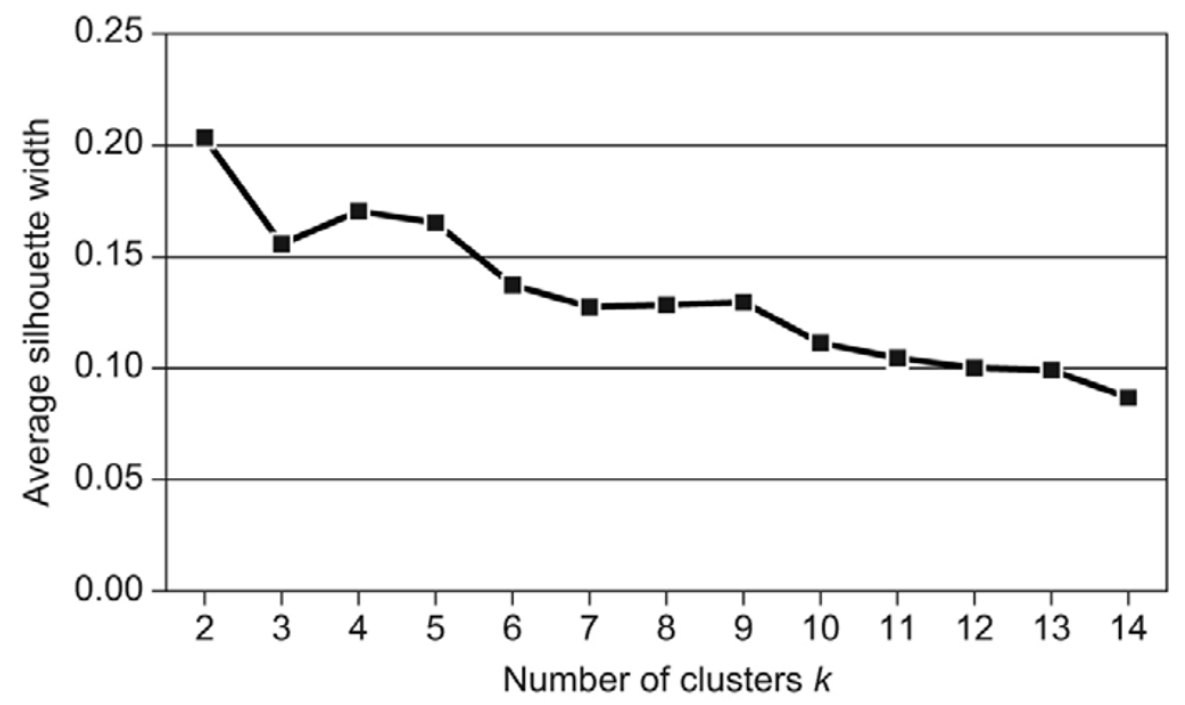

Taking Figure 3 first, a better cluster solution will have an average value closer to 1 than 0 . While Kaufman and Rousseeuw (2005) state that an average silhouette width $<0.25$ represents a poor cluster, Shepherd (2006) successfully employs the technique to assess cluster solutions with average values of around 0.1 . It is evident that generally, as the number of clusters increases, the average silhouette value decreases, indicating at least for this metric, fewer clusters represent a more desirable solution. Taking Figure 4 also into consideration, however, a different conclusion might be reached. If we accept that more evenly sized groups are the most desirable outcome, then lower values in Figure 4 represent the better solution. Here clusters of 7, 8, 10, 13 and 14 groups could be candidates for selection. Using both of these measures, it would appear that three clusters could be a good overall solution. A classification with only three clusters, however, is undesirable as fewer groups will represent much broader generalisations in the data. If somewhere between the six clusters suggested by Vickers (2006) and the eight clusters suggested by the initial classification is aimed for, then Figure 4 suggests that solutions with either seven or eight clusters might be suitable as they both perform relatively well in both tests. With comparable scores in both metrics a decision between the two is a difficult one to make. The silhouette plots for 
both (Figure 5) enabling an assessment of the quality of each individual cluster are also very comparable, where perhaps if one solution featured a cluster with a large negative spike (representing a number of cases which could be very easily associated with another cluster) it would be a clear candidate for being dropped; here no such spikes are apparent, so additional data are required to assist the decision - these are shown in Table 4.

\section{Figure 4 Absolute average differences from mean cluster size for solutions between 2 and 14 clusters}

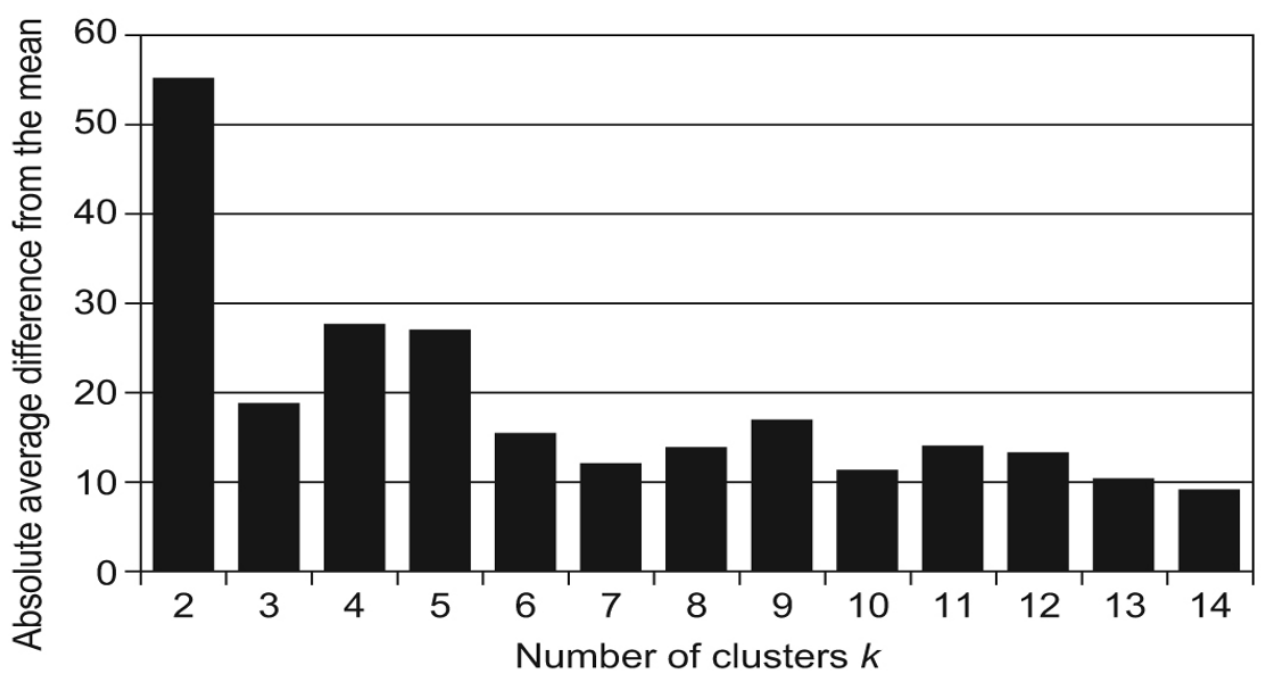

Figure $5 \quad$ Silhouette widths for 7 and 8 cluster solutions - k-means, Manhattan distance, 200 replicates

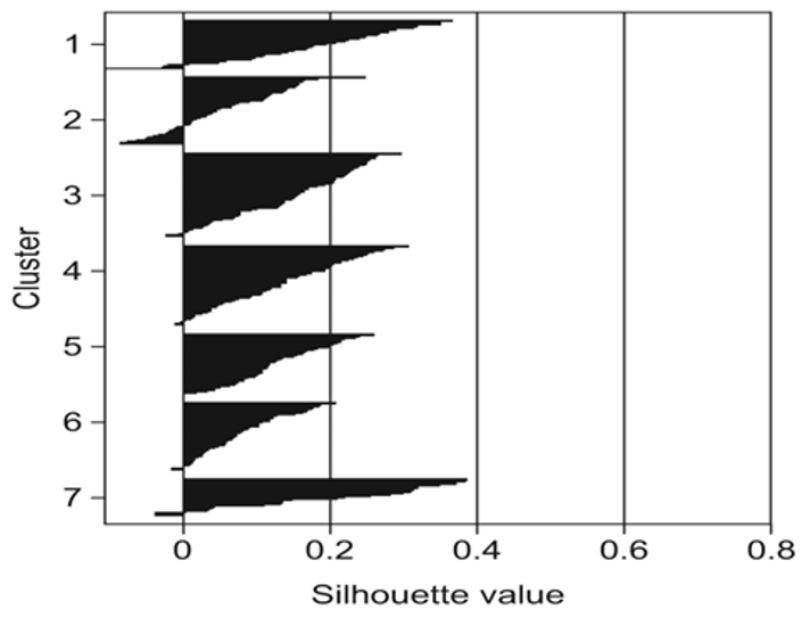

a. 7 cluster solution

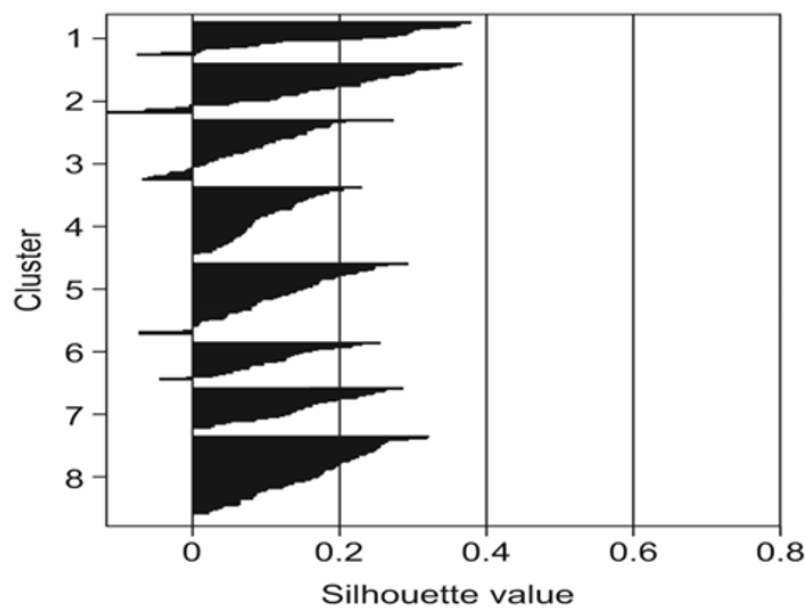

b. 8 cluster solution

Where cluster solutions have similar average silhouette values, as is the case here, it is likely that the better solution would be the one with fewer values below 0 as these values indicate badly assigned objects. As Table 4 shows, while both cluster solutions have similar average silhouette values and similar counts of silhouette values below 0 , the sum of the $<0$ silhouette values for seven clusters is worse than it is for eight clusters, indicating that where cases have weak associations with the clusters they have been assigned to, these weak associations are worse in a 
seven cluster solution. Therefore taking all of this evidence into consideration - as well as the assertion by Milligan (1996 quoted in Shepherd, 2006) that where there is doubt, the higher figure should be taken - we will use an eight cluster solution for the final classification.

\section{Table 4 Summary of silhouette data for $\mathbf{k}=\mathbf{7}$ and $\mathbf{k}=\mathbf{8}$ cluster solutions}

\begin{tabular}{|l|l|l|l|l|}
\hline Cluster & Cases in cluster & Count Silhouette $<\mathbf{0}$ & Sum Silhouette <0 & Avg Silhouette \\
\hline 1 & 73 & 1 & -0.004 & 0.133 \\
2 & 78 & 3 & -0.028 & 0.146 \\
3 & 45 & 4 & -0.153 & 0.188 \\
4 & 55 & 0 & 0.000 & 0.123 \\
5 & 63 & 2 & -0.033 & 0.080 \\
6 & 33 & 2 & -0.073 & 0.204 \\
7 & 61 & 14 & -0.433 & 0.065 \\
\hline $\mathbf{7}$ cluster solution & $\mathbf{4 0 8}$ & $\mathbf{2 6}$ & $-\mathbf{0 . 7 2 3}$ & $\mathbf{0 . 1 2 8}$ \\
\hline 1 & 65 & 5 & -0.066 & 0.119 \\
2 & 39 & 4 & -0.028 & 0.104 \\
3 & 45 & 6 & -0.238 & 0.172 \\
4 & 37 & 1 & -0.002 & 0.148 \\
5 & 75 & 1 & -0.004 & 0.152 \\
6 & 53 & 8 & -0.262 & 0.082 \\
7 & 31 & 3 & -0.037 & 0.197 \\
8 & 63 & 0 & 0.000 & 0.098 \\
\hline $\mathbf{8}$ cluster solution & $\mathbf{4 0 8}$ & $\mathbf{2 8}$ & $-\mathbf{0 . 6 3 7}$ & $\mathbf{0 . 1 3 0}$ \\
\hline
\end{tabular}

\section{Results: The CIDER Migration Classification}

Having outlined the methodology employed to build the classification in the last section, we now present the final eight cluster CIDER Migration Classification typology. Figure 6 shows a map of the clusters as they define the 408 districts in Britain. The names used are descriptive and seek to summarise and represent the distinct profile of each cluster; a more detailed description is provided below. For a detailed breakdown of the variables defining each cluster, and the strength of association each district has with the cluster it is a member of (silhouette data), see Dennett and Stillwell (2009). To access a look-up table to aggregate local authority districts into the Migration Classification, visit: http://cider.census.ac.uk/cider/about/data geog.php

\section{Cluster 1: Coastal and Rural Retirement Migrants}

Cluster 1 is dominated by coastal and rural areas, particularly in the South West, Kent, Norfolk, the south coast, Wales and Scottish borders and Highlands. The Isle of Wight is the district most representative of this cluster, with Blackpool the district most unrepresentative - mainly thanks to a noticeable net out-migration of those in the highest three socio-economic groups. The cluster is characterised by in-migrants and within-area migrants in the older age groups - 45 and above. Younger in-migrants are very much underrepresented. Migrants into these areas are from across the socio-economic spectrum, although the very high socio-economic groups are less common. 
Migrants preferentially move into owner occupied accommodation, and tend to be either alone or in couples, far more than parent families.

\section{Figure 6 The CIDER Internal Migration District Classification}

The Migration Classification 8 Cluster Groups

1 - Coastal and Rural Retirement Migrants

2 - Low-Mobility Britain

3 - Student Towns and Cities

4 - Moderate Mobility, Non-Household, Mixed Occupations

5 - Declining Industrial, Working-Class, Local Britain

6 - Footloose, Middle-Class, Commuter Britain

7 - Dynamic London

8 - Successful Family In-migrants

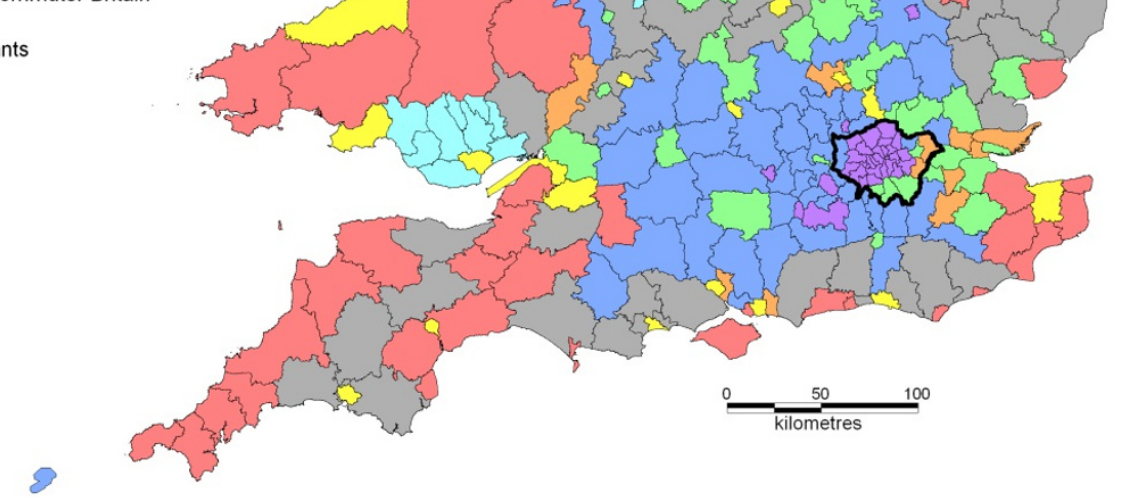




\section{Cluster 2: Low-Mobility Britain}

Cluster 2 is spread around Britain, although small concentrations exist in the Midlands moving into south Merseyside, and to the south and east of London. North East Derbyshire is the most representative district in this cluster, with Erewash and South Bedfordshire most likely to be misclassified. The cluster is characterised by very little internal migration activity, with in-migration and out-migration under-represented across all age groups. Within-area migration is particularly under-represented. Where in-migration does occur it tends to be into owner-occupied housing and by migrants in slightly higher socio-economic groups.

\section{Cluster 3: Student Towns and Cities}

Cluster 3 is comprised principally of larger towns and cities housing universities and higher education institutions. Newcastle-upon-Tyne is the most representative district, with Luton being the least representative. Despite a strong average silhouette value, signifying a well-defined cluster, six districts including Luton have very weak associations. The cluster is characterised by high levels of net student in-migration, and young person in- and within-area migration. Nonhousehold moving groups into privately rented accommodation are common in this cluster, as are non-family households and individuals moving into communal establishments - all characteristics of a student population. In addition, non-white within-area migration is important, as is in-migration of economically inactive migrants.

\section{Cluster 4: Moderate Mobility, Non-Household, Mixed Occupations}

Cluster 4 is the second smallest cluster, with districts tending to be found in the south and Midlands. While small, it is reasonably well defined, with only Wrexham having a noticeably ambiguous membership. Croydon is the district with the characteristics most representing this cluster. The cluster features relatively low levels of migration in general, although migrants moving into these areas are more likely to be engaged in intermediate occupations. Migrants who move alone or in non-family households are also more common in areas in this cluster. Wholly moving households and owner occupiers are less common.

\section{Cluster 5: Declining Industrial, Working-Class, Local Britain}

Cluster 5 is the largest cluster and is concentrated mainly around the ex-industrial areas of South Wales, Yorkshire, Greater Manchester and Lancashire, the North-East and Scotland. The cluster is also well defined with only North Lincolnshire having a silhouette value lower than 0 . Districts in this cluster have very much below average in-migration and out-migration for all age groups, signifying a degree of isolation from other districts (in the same and different clusters) in Britain. Shorter distance, within-area migration is slightly above average. Moves into these areas come from individuals in the lower socio-economic groups, with moves of one-parent families being above average. Moves of economically inactive individuals, however, are very much below average.

\section{Cluster 6: Footloose, Middle-Class, Commuter Britain}

Cluster 6 is the most poorly defined cluster, with the lowest average silhouette value. Eight districts out of the 58 have silhouette values lower than 0 . The most representative district of the cluster is Waverley. In general, districts in this are concentrated just outside of London in the Home Counties and heading out west along the M3/M4 corridor. This cluster is characterised by higher rates of in and out-migration, particularly in the below 30 age groups. Within area migration is very much 
below average. Out-migration rates of economically inactive individuals are much higher than average. Migration efficiency rates are very negative for lower socio-economic groups, but positive for those in higher groups.

\section{Cluster 7: Dynamic London}

Cluster 7 is almost entirely concentrated within Greater London - only Cambridge, Reading, Guildford and Runnymede fall outside the M25. The cluster is defined by some of the highest and lowest z-score values, indicating it is the most dynamic cluster in the classification. It features very high rates of in-migration for the migrants under 30 , but below average in-migration rates for those over 30. Out-migration rates are very high for all groups, but especially for those between 30 and 45. Within area migration rates are much below average (possibly a function of the compactness of the cluster and the proximity of most of the zones and the life-course motivations of moves from inner London boroughs to outer London), as are those of non-whites (except those with noprevious address). This cluster features the highest rates of movement of the economically inactive. Across the four highest socio-economic groups there are positive efficiency rates for other moving groups, but negative rates for wholly moving households, indicating if whole households move, they leave these areas, whereas non-households individuals tend to move in - especially into privately rented accommodation. Students are also an important group of in-migrants to this cluster. Families (both couples and single parents) are noticeably moving out of this cluster.

\section{Cluster 8: Successful Family In-migrants}

Cluster 8 is located mainly in rural areas of England, and is distributed quite evenly across the country. The cluster is relatively well defined as no districts have negative silhouette values. Wychavon is the most representative district in this cluster. In-migration of all age groups above 30 is above average, with importance increasing as age increases. Within-area migration is less significant. There are positive, in-migration balances across all socio-economic groups, although there are noticeable out-migrations of students from this cluster. When migrants move into this cluster, the preference is to move into owner occupied accommodation, with couple families being more important than any other group.

\section{Conclusions}

In this article we have presented a new internal migration-based classification of local authority districts for Britain. At the beginning of the article we defined two principal research questions. The first asked why the readily available general-purpose classifications already in existence are not wholly sufficient for assisting internal migration analysis. It was demonstrated, initially, that due to the limitations inherent in the quality (census migration data below the level of local authority district are heavily affected by disclosure control perturbation) and availability (non-census internal migration data are not available below the district level) of internal migration data, a limited selection of district-level classifications were the only currently available option for reducing the origin/destination dimensions of internal migration matrices. We then show that across the 408 districts in Britain and across a range of census domains, the internal migrant population varies significantly from the settled population, increasing the likelihood that in using general purpose classifications, important flow patterns might be obscured by the underlying population structures defining them. Thus where these existing general purpose classifications do not offer the best solution for the analysis of district level internal migration data, a new migration-based classification offers a potential solution. An additional benefit of creating such a new classification 
is that both the process of arriving at the final solution and the final typology itself will reveal some of the most important features of the internal migration landscape of Britain: the variables which help define the flows and the areas which share similar migrant characteristics.

In the second half of the article, we answered the second research question which asked what a new migration-based area classification typology would consist of, look like and reveal about the internal migration in Britain. In outlining some of the key methodological points and decisions we showed that the CIDER Migration Classification consists of 44 variables taken from across several different census internal migration domains. It was established that while adopting an established classification building methodology, some elements of the process such as the implementation of the k-means algorithm in different software packages, can be altered to produce a more robust final solution. The final classification consists of eight clusters, each with a distinct internal migration profile; these profiles have produced a new geography for Britain showing, for example, the heavy dominance of the central 'Dynamic London' boroughs in the migration system, both attracting young migrants and then distributing migrants later in their lives; the importance of 'Student Towns and Cities' as a destination for young migrants; or the relative isolation from the rest of the national system of districts in the 'Declining Industrial, Working-Class, Local Britain' cluster.

The multifaceted and ultimately heuristic nature of classification building means that no solution can be regarded as perfect, with a different choice of variables, clustering algorithm or number of clusters liable to produce a different solution each time. However, we hope to have demonstrated that through sound decisions made at each stage of the process a useful typology can be produced which now already enhances our understanding of the internal migration landscape of Britain through rich descriptions of the cluster compositions and their spatial distributions. Of course the real test of the success of the classification will come through its use as a framework for further analysis of migration flows. As we point out in the introduction to this article, an analysis of comparable internal migration data using the Migration Classification and another general purpose classification should confirm the wider utility of our new typology in preference to others; this is certainly work which should be carried out in the future. Wider applicability has to an extent already been shown with work by Stillwell and Dennett (forthcoming) demonstrating the utility of the classification in the context of ethnic migration, and Dennett (2010) using the classification as a tool for monitoring internal migration in Britain since 2001. In presenting this new typology here, we hope that there will be continuing scope for the application of the Migration Classification in other internal migration analyses in the future. 


\section{Key Findings}

- Characteristics of the internal migrant population differ noticeably from those of the general population

- As such general purpose area classifications built from data on total populations are not the best vehicle for analysing internal migration flows; flow concentrations (such as students into university towns) can be masked where these areas are defined by different population characteristics

- Internal migration data, disaggregated by age, ethnicity, socio-economic status, economic activity, housing tenure, family status and type of move (in to, out of or within an area) can be clustered to produce a typology of areas in Britain

- Care should be taken when building classifications to choose appropriate methods to select variables and cluster areal units - whilst many pieces of software will perform a cluster analysis, not all will provide the most reliable final solution

- Clusters of local authority districts can be observed with distinct internal migration profiles within the CIDER Migration Classification; for example the 'Successful Family In-Migrants' cluster located in non-metropolitan, mainly rural areas, with high levels of migrants aged 3044 moving in, and a significant volume of student-age outmigration

- The CIDER Migration Classification provides a new and more useful framework for analysing internal migration flows in Britain

\section{Acknowledgements}

This work is partly supported by funding from the Economic and Social Research Council (ESRC) through a Census Programme grant (RES-348-25-0005). All data and classification details are available from http://cider.census.ac.uk/

\section{References}

Aggarwal, C.C., Hinnenburg, A., \& Keim, D.A. (2001). On the surprising behaviour of distance metrics in high dimensional space, Lecture Notes in Computer Science, 1973, 420-34.

Bailey, S., Charlton, J., Dollamore, G., \& Fitzpartick, J. (2000). Families, groups and clusters of local and health authorities: revised for authorities in 1999, Population Trends, 99, 37-52.

Bates, J. and Bracken, I. (1982). Estimation of migration profiles in England and Wales, Environment and Planning A, 14(7), 889-900. 
Bell, M., Blake, M., Boyle, P., Duke-Williams, O., Rees, P., Stillwell, J., \& Hugo, G. (2002). Crossnational comparison of internal migration: issues and measures, Journal of the Royal Statistical Society Series a-Statistics in Society, 165, 435-64.

Bohara, A.K.,\&Krieg, R.G. (1998). A simultaneous multinomial logit model of indirect internal migration and earnings, Journal of Regional Analysis and Policy, 28 (1), 60-72.

Böheim, R., \& Taylor, M.P. (2002). Tied down or room to move? Investigating the relationships between housing tenure, employment status and residential mobility in Britain, Scottish Journal of Political Economy, 49(4), 369-92.

Boyle, P. (1998). Migration and housing tenure in South East England, Environment and Planning A, 30, 855-66.

Boyle, P., Cooke, T., Halfacree, K., \& Smith, D. (1999). Intregrating GB and US census microdata for studying the impact of family migration on partnered women's labour market status, International Journal of Population Geography, 5, 157-78.

Cameron, G., Muellbauer, J., \& Murphy, A. (2005). Migration within England and Wales and the housing market, Royal Economic Society Annual Conference.

Castro, L.J., \& Rogers, A. (1981). Status-specific age patterns of migration: family status, IIASA Working Paper WP-81-060 International Institute for Applied Systems Analysis, Laxenburg.

CEC (2008). Regions 2020 - An Assessment of Future Challenges for EU Regions, Commission of the European Communities, Brussels. (http://ec.europa.eu/regional policy/index en.htm).

Champion, A.G. (2005). Population movement within the UK, in R Chappell (Ed.), Focus on people and migration, Focus On; Basingstoke: Palgrave Macmillan, 92-114.

Champion, A.G. \& Coombes, M. (2010). Migration and socio-economic polarisation within British city regions, in Stillwell, J. Duke-Williams, O. and Dennett, A. (eds.) Technologies for Migration and Commuting Analysis: Spatial Interaction Data Applications, (pp. 196-211). IGI Global, Hershey.

Champion, A.G., Coombes, M., Raybould, S., \& Wymer, C. (2007). Migration and socio-economic change: A 2001 census analysis of Britain's larger cities, Joseph Rowntree Foundation, Bristol.

Chappell, R., Vickers, L., and Evans, H. (2000), 'The use of patient registers to estimate migration', Population Trends, 101, 19-24.

Clark, W. \& Huang, Y. (2004). Linking migration and mobility: Individual and contextual effects in housing markets in the UK, Regional Studies, 38(6), 617 - 28.

Cooke, T. J. (2008). Migration in a family way, Population Space and Place, 14(4), 255-65.

Cooke, T.J., \& Bailey, A.J. (1999). The effect of family migration, migration history, and selfselection on married women's labour market achievement. In P. Boyle and K. Halfacree (eds.), Migration and gender in the developed World; (pp. 102-13). London: Routledge. 
Coombes, M. (2002). Travel to work areas and the 2001 census, Centre for Urban and Regional Development Studies, University of Newcastle, Newcastle.

Coombes, M., Green, A., \& Openshaw, S. (1986). An efficient algorithm to generate official statistical reporting areas: the case of the 1984 travel-to-work areas revision in Britain, Journal of the Operational Research Society, 37(10), 943-53.

Coombes, M., Raybould, S., \& Wymer, C. (2004). Analysis of census migration data to assist in defining housing market areas for Tyne and Wear, Centre for Urban and Regional Development Studies, University of Newcastle Upon Tyne, Newcastle Upon Tyne.

Dennett, A. (2010) 'Understanding internal migration in Britain at the start of the 21st Century' PhD Thesis, University of Leeds

Dennett, A., \& Stillwell, J. (2009). A new migration classification for local authority districts in Britain, Working Paper 09/2, School of Geography, University of Leeds, Leeds.

Dennett, A., \& Stillwell, J. (2010a). Internal Migration Patterns by Age and Sex at the Start of the 21st Century. In J. Stillwell, O. Duke-Williams, and A. Dennett (Eds.), Technologies for Migration and Commuting Analysis: Spatial Interaction Data Applications. (pp. 280-293). Hershey: IGI Global.

Dennett, A., \& Stillwell, J. (2010b). Internal migration in Britain, 2000-01, examined through an area classification framework, Population, Space and Place, 16(6), 517-38.

Dennett, A., Duke-Williams, O., \& Stillwell, J. (2007). Interaction data sets in the UK: an audit, Working Paper 07/05, University of Leeds, Leeds.

Dixon, S. (2003). Migration within Britain for job reasons, Labour Market Trends, April, 191-201.

Duke-Williams, O. (2010). Mapping the geodemographic classifications of migrants' origins and destinations, Journal of Maps, v2010, 360-69.

Duke-Williams, O., \& Stillwell, J. (2007). Investigating the potential effects of small cell adjustment on interaction data from the 2001 Census, Environment and Planning A, 39, 1079-100.

Everitt, B.S., Landau, S., \& Leese, M. (2001). Cluster Analysis 4th edn., London: Arnold.

Faggian, A., McCann, P., \& Sheppard, S. (2006). An analysis of ethnic differences in UK graduate migration behaviour, Annals of Regional Science, 40, 461-71.

Fielding, A.J. (1992). Migration and social mobility: South East England as an escalator region, Regional Studies, 26 (1), 1-15.

Findlay, A., Mason, C., Houston, D., McCollum, D., \& Harrison, R. (2009). Escalators, elevators and travelators: The occupational mobility of migrants to South-East England, Journal of Ethnic and Migration Studies, 35(6), 861-79. 
Finney, N., \& Simpson, L. (2008). Internal migration and ethnic groups: evidence for Britain from the 2001 census, Population Space and Place, 14, 63-83.

Finney, N. and Simpson, L. (2009). Population dynamics: The roles of natural change and migration in producing the ethnic mosaic, Journal of Ethnic and Migration Studies, 35(9), 1479-96.

Geist, C., \& McManus, P. A. (2008). Geographical mobility over the life course: Motivations and implications, Population, Space and Place, 14(4), 283-303.

Kaufman, L., \& Rousseeuw, P.J. (2005). Finding groups in data - an introduction to cluster analysis. New Jersey: John Wiley \& Sons.

Larkin, K. (2010). Local enterprise partnerships: centre for cities' 6-step plan, Centre for Cities, London. (www.centreforcities.org/).

MathWorks (2009). MATLAB Statistics Toolbox 7 - User's Guide; Natick: The MathWorks Inc.

Milligan, G.W. (1996). Clustering validation: results and implications for applied analyses. In P. Arabie, L.J. Hubert, and G. De Soete (Eds.), Clustering and Classification. (pp. 341-75).

Singapore: World Scientific.

Milligan, G.W. \& Cooper, M.C. (1987). Methodology review: Clustering methods, Applied Psychological Measurement, 11, 329-54.

Milligan, G.W., \& Cooper, M.C. (1988). A study of standardization of variables in cluster analysis, Journal of Classification, 5, 181-204.

Murphy, A., Muellbauer, J., \& Cameron, G. (2006). Housing market dynamics and regional migration in Britain, Discussion Paper Series, Department of Economics, University of Oxford, Oxford.

Norman, P., Boyle, P. and Rees, P. (2005). Selective migration, health and deprivation: a longitudinal analysis, Social Science \& Medicine, 60(12), 2755-71.

ONS (2011). Subnational Population Projections for England. www.ons.gov.uk/ons/taxonomy/index.html?nscl=Sub-national+Population+Projections

Openshaw, S. \& Wymer, C. (1995). Classifying and regionalizing census data. In S. Openshaw (Ed.), Census Users' Handbook. Cambridge: Geoinformation International.

Owen, D. (1997). Migration by minority ethnic groups within Great Britain in the early 1990s, 28th annual conference of the British and Irish section of the Regional Science Association International (Falmouth College of Arts).

Ravenstein, E.G. (1889). The laws of migration, Journal of the Royal Statistical Society, 52(2), 241305.

Ravenstein, E.G. (1885). The laws of migration, Journal of the Statistical Society of London, 48(2), 167-235. 
Raymer, J. \& Rogers, A. (2007). Using age and spatial flow structures in the indirect estimation of migration streams, Demography, 44(2), 199-223.

Raymer, J., \& Giulietti, C. (2009). Ethnic migration between area groups in England and Wales, Area, 414$), 435-51$.

Raymer, J., Bonaguidi, A., \& Valentini, A. (2006). Describing and projecting the age and spatial structures of interregional migration in Italy, Population Space and Place, 12(5), 371-88.

Raymer, J., Smith, P.W.F., \& Giulietti, C. (2009). Combining census and registration data to analyse ethnic migration patterns in England from 1991 to 2007, Population, Space and Place, doi 10.1002/psp.565.

Rees, P., Durham, H., \& Kupiszewski, M. (1996). Internal migration and regional population dynamics in Europe: United Kingdom case study, Working Paper, School of Geography, University of Leeds, Leeds, (12/3/07).

Rees, P., Boden, P., Dennett, A., Stillwell, J., Jasinska, M., de Jong, A., ter Veer, M., Kupiszewski, M., \& Kupiszewska, D. (2010). Regional population dynamics: a report assessing the effects of demographic developments on regional competitiveness and cohesion, ESPON, Luxembourg.

Rogers, A., \& Castro, L.J. (1981). Model migration schedules, Research Report-81-30, International Institute for Applied Systems Analysis, Laxenburg, Austria. (www.iiasa.ac.at/Admin/PUB/Documents/RR-81-030.pdf).

Rogers, A., Raymer, J., \& Willekens, F. (2002). Capturing the age and spatial structures of migration, Environment and Planning A, 34(2), 341-59.

Rousseeuw, P. J. (1987). Silhouettes: A graphical aid to the interpretation and validation of cluster analysis, Journal of Computational and Applied Mathematics, 20, 53-65.

Schaffer, C.M., \& Green, P.E. (1996). An empirical comparison of variable standardisation methods in cluster analysis, Multivariate Behavioural Research, 31 (2), 149-67.

Shepherd, P.J (2006). Neighbourhood profiling and classification for community safety, PhD Thesis (University of Leeds).

Simpson, L., \&Finney, N. (2009). Spatial patterns of internal migration: evidence for ethnic groups in Britain, Population, Space and Place, 15, 37-56.

Sjaastad, L.A. (1962). The costs and returns of human migration, The journal of Political Economy, 70(5), 80-93.

Stillwell, J. (2010a). Ethnic population concentration and net migration in London, Environment and Planning A, 42: 1439-1456.

Stillwell, J. (2010b). Internal migration propensities and patterns of London's ethnic groups, in Stillwell, J. Duke-Williams, O. \& Dennett, A. (eds.) Technologies for Migration and Commuting Analysis: Spatial Interaction Data Applications, (pp. 175-195). IGI Global, Hershey. 
Stillwell, J., \& Duke-Williams, O. (2007). Understanding the 2001 UK census migration and commuting data: the effect of small cell adjustment and problems of comparison with 1991, Journal of the Royal Statistical Society Series A (Statistics in Society), 170 (2), 425-45.

Stillwell, J., \& Dennett, A. (Forthcoming). A comparison of internal migration by ethnic group in Great Britain using a district classification, Journal of Population Geography.

Stillwell, J., Hussain, S., \& Norman, P. (2008). The internal migration propensities and net migration patterns of ethnic groups in Britain, Migration Letters, 5(2), 135-50.

Uren, Z., \& Goldring, S. (2008). Migration trends at older ages in England and Wales, Population Trends, 130, 31-40.

Vickers, D., \& Rees, P. (2006). Introducing the area classification of output areas, Population Trends, (125), 15-29.

Vickers, D., \& Rees, P. (2007). Creating the UK National Statistics 2001 output area classification, Journal of the Royal Statistical Society Series a-Statistics in Society, 170 (2), 379-403.

Vickers, D., Rees, P., \& Birkin, M. (2003). A new classification of UK local authorities using 2001 Census key statistics, University of Leeds - Working Paper 03/03 